\title{
OS PLANOS DE SAÚDE E A COBERTURA DE HOME CARE
}

Health insurance and home care coverage

${ }^{1}$ Pontifícia Universidade Católica do Rio Grande do Sul. Porto Alegre/RS, Brasil. Correspondência: Augusto Franke Dahinten. E-mail: gutodahinten@yahoo.com.br

Recebido: 07/11/2018. Revisado: 08/05/2019. Aprovado: 10/06/2019. 


\section{RESUMO}

As solicitações de cobertura para home care estão entre as mais complexas discussões hoje existentes no universo jurídico dos planos de saúde. A partir de um estudo normativo-jurisprudencial, o presente artigo tem como objetivo examinar os serviços de saúde domiciliares à luz das coberturas dos contratos de planos de saúde. Com esta meta, passa por diversos tópicos inerentes a este assunto, incluindo determinados fenômenos jurídicos e sociais que ajudam a entendê-lo, assim como o regime jurídico que regula a matéria. Na sequência, o artigo foca os serviços domiciliares, com ênfase naqueles que, à luz das normas aplicáveis, são considerados como de cobertura obrigatória. Após, comenta também a complexidade terminológica que envolve o tema. Ao final, passa ao exame da jurisprudência existente sobre planos de saúde e cobertura para serviços domiciliares, com destaque para os recentes precedentes que, na opinião dos autores, adotam uma posição mais aceitável e razoável, capaz de representar um verdadeiro ponto de equilíbrio a esta temática tão controvertida.

\section{Palavras-Chave:}

Coberturas Obrigatórias; Contratos de Planos de Saúde; Home Care; Serviços de Saúde Domiciliares; Sistema de Saúde Suplementar.

\section{ABSTRACT}

Demands for home care coverage are stirring the most complex discussions currently existing in the legal universe of health insurance contracts. Based on a normative-jurisprudential study, this essay's scope examines home health care services in light of the coverage of health insurance contracts. With this goal, several topics on the subject are dealt with, including certain juridical and social phenomena that facilitate its understanding, as well as the legal regime that regulates this matter. It follows focusing on home health care services, with emphasis on those that, in light of the applicable regulatory standards, are considered to be of compulsory coverage. Next, the terminological complexity that involves this subject is also commented. At the end, the existing jurisprudence regarding health care insurances and the coverage for home health care services is examined, highlighting recent precedents that, in the authors' opinion, adopt an acceptable and reasonable position, capable of representing a true balance point for this controversial matter.

\section{Keywords:}

Compulsory Coverage; Health Insurance Contracts; Home Care; Home Health Care Services; Supplementary Health System. 


\section{Introdução}

Sabe-se que, por diversas razões, os serviços públicos de saúde no Brasil são insuficientes e incapazes de atender à integralidade da população. Esta realidade impulsionou, nas últimas décadas, o crescimento e a consolidação do mercado da saúde suplementar, podendo-se afirmar, com segurança, que os planos de saúde desempenham hoje papel importantíssimo no que tange à satisfação das necessidades dos brasileiros na área de saúde.

É igualmente verdade, de outro lado, que os planos privados de assistência à saúde são relações jurídicas complexas e que, embora se submetam a uma vastidão de normas regulamentadoras, possuem incontáveis aspectos controvertidos. Dentre as diversas questões do universo da saúde suplementar que se sujeitam a contínuas discussões judiciais e extrajudiciais, destaca-se a polêmica relativa à cobertura e ao fornecimento de serviços e/ou atendimentos domiciliares (home care).

Trata-se de um assunto atualíssimo, visto que, nos últimos anos, se proliferaram as solicitações por serviços de saúde a serem prestados em domicílio. É também um tema muito delicado, em razão das repercussões sociais e econômicas que dele decorrem, seja para o paciente e seus familiares, seja para as operadoras de planos de saúde. É, ainda, uma temática complexa e confusa, na medida em que sua análise envolve um regime jurídico específico, além de trabalhar com expressões imprecisas e ambíguas.

Não se ignora que as problemáticas atinentes ao fornecimento de atendimentos domiciliares sejam, ainda que com particularidades, igualmente compartilhadas pelos serviços públicos de saúde. Ainda assim, e muito embora diversos dos aspectos que serão aqui comentados também se apliquem à realidade dos serviços públicos, o presente estudo pretende focar o âmbito dos contratos privados de assistência à saúde e seu regime jurídico.

Assim, o presente texto, a partir de um estudo normativo-jurisprudencial, pretende examinar precisamente este assunto, isto é, os serviços domiciliares e a obrigatoriedade, ou não, de sua cobertura pelos planos de saúde, contemplando a importância e a atualidade do tema, analisando as imprecisões terminológicas que o permeiam, examinando a legislação e as normas aplicáveis e, ao final, avaliando a principal jurisprudência existente sobre a matéria.

\section{O home care e os serviços de saúde}

Antes de se adentrar propriamente no tema deste trabalho, uma verdade há de ser consignada: do ponto de vista jurídico, combinar home care (ou atendimento domiciliar) e planos de saúde é trilhar um caminho complexo. E a compreensão dessa realidade requer alguns comentários preliminares acerca dos seguintes fenômenos que influenciam determinantemente a análise do assunto. 
(i) O atual momento jurídico-constitucional: acompanhando tendência mundial, o Brasil inaugurou, com a Constituição Federal de 1988 (CF/88), uma nova era jurídica e constitucional, marcada pelo reconhecimento e pela consagração dos valores humanos e sociais. Fundada no princípio da dignidade da pessoa humana, a Carta Magna positivou uma série de direitos e garantias fundamentais, direcionada à valorização dos seres humanos, aos direitos de personalidade, à igualdade material e aos valores sociais. É inquestionável que se vive, portanto, um momento jurídico-constitucional humanizado, centrado na pessoa humana e que privilegia direitos e valores sociais ${ }^{1}$.

(ii) A positivação do direito à saúde: entre os direitos fundamentais positivados no texto da $\mathrm{CF} / 88^{2}$, destaca-se o direito à saúde (art. $6^{\circ}$ ), consagrado como um direito de todos e um dever do Estado (art. 196), a ser viabilizado mediante políticas públicas, sem prejuízo da possibilidade de complementação pela iniciativa privada (art. 197). Do ponto de vista constitucional, destarte, o acesso aos serviços de saúde decorre de um direito fundamental, cujo fornecimento compete precipuamente ao Estado.

(iii) A expansão do sistema de saúde suplementar: em que pese o texto constitucional tenha assegurado a universalidade do direito à saúde, a ser garantido pelo poder público, sabe-se que os serviços públicos de saúde são incapazes de atender a toda a população. Expandiu-se, assim, o chamado sistema de saúde suplementar, cujos principais produtos são os seguros e planos de saúde. Trata-se de atividade econômica hiper-regulada, que se submete a regime jurídico próprio e que é hoje protagonista no que concerne aos serviços de saúde 3 .

(iv) A excessiva judicialização das relações sociais: existe no Brasil uma forte tendência de buscar a resolução de conflitos sociais no Poder Judiciário. Seja pela burocracia das vias administrativas, seja pela insuficiência das leis, seja pela relutância nas composições amigáveis, entre outras causas, fato é que as desavenças sociais são constantemente judicializadas. Os serviços de saúde são o maior exemplo dessa realidade, com milhares de ações judiciais propostas com intuito de obter o fornecimento de alguma espécie de serviço de saúde ${ }^{4}$.

\footnotetext{
${ }^{1}$ FACCHINI NETO, Eugênio. Reflexões históricos-evolutivas sobre a Constitucionalização do Direito Privado. In: SARLET, Ingo Wolfgang (Org.). Constituição, direitos fundamentais e direito privado. 3. ed. Porto Alegre: Livraria do Advogado, 2010.

2BRASIL. Constituição da República Federativa do Brasil de 1988. Disponível em: http://www.planalto.gov. br/ccivil_03/constituicao/constituicaocompilado.htm. Acesso em: 20 fev. 2020.

${ }^{3}$ SCAFF, Fernando Campos. Direito à saúde no âmbito privado: contratos de adesão, planos de saúde e seguro-saúde. São Paulo: Saraiva, 2010.

${ }^{4}$ CARLINI, Angélica. Judicialização da saúde pública e privada. Porto Alegre: Livraria do Advogado, 2014 e SCHULZE, Clenio Jair; NETO, João Pedro Gebran. Direito à saúde: análise à luz da judicialização. Porto Alegre: Verbo Jurídico, 2015.
} 
(v) A proteção dos consumidores: desde 1990, com a publicação do Código de Defesa do Consumidor (CDC) $)^{5}$, os consumidores no Brasil contam com a tutela protetiva do Estado. A proteção do consumidor tem status de direito fundamental e implica, na prática, uma série de direitos em favor dos consumidores, incluindo, por exemplo, direito à informação clara, à revisão de cláusulas contratuais abusivas e à facilitação de sua defesa em juízo. Os contratos de planos de saúde, como regra, formam relações de consumo e, como tal, atraem todo o arcabouço normativo existente em favor dos consumidores ${ }^{6}$.

(vi) A proliferação de decisões individualistas: seja pela confusão que existe entre direito universal à saúde (imposto ao poder público por força da $\mathrm{CF} / 88$ ) e direitos contratuais (impostos às operadoras por força de contratos), seja pela (não raro exagerada) aplicação das normas de proteção dos consumidores, fato é que os conflitos judiciais que versam sobre serviços de saúde tendem a ser resolvidos favoravelmente aos demandantes (beneficiários de planos de saúde). Essa realidade é especialmente verdadeira no âmbito dos planos privados, cujas limitações contratuais, notadamente no âmbito das coberturas assistenciais, dificilmente são validadas em juízo. A disseminação desse fato contribui ainda mais para o incremento das ações judiciais que tratam de serviços de saúde ${ }^{7}$.

(vii)O fenômeno do envelhecimento populacional: o aumento da idade é naturalmente acompanhado do aumento de doenças e de agravos à saúde. Como decorrência, os serviços de saúde passam a integrar a rotina das pessoas que deles dependem. Problemas e discussões envolvendo o fornecimento de tais serviços ganham, igualmente, maior destaque e relevância. Com o aumento da idade das pessoas e da maior longevidade, aumentam também a utilização e a dependência dos serviços de saúde.

Acresce-se aos fenômenos acima elencados o fato de que os planos de saúde, como regra, não cobrem atendimentos domiciliares. Como consequência, o cenário que se revela é caótico: os serviços domiciliares, cada vez mais prescritos em razão do envelhecimento populacional, tendem a ser negados administrativamente. Como decorrência - sobretudo no âmbito dos planos privados, nos quais incidem as normas protetivas dos consumidores -, tende-se a buscar judicialmente a cobertura para esses serviços.

\footnotetext{
${ }^{5}$ BRASIL. Lei n. 8.078, de 11 de setembro de 1990. Dispõe sobre a proteção do consumidor e dá outras providências. Disponível em: http://www.planalto.gov.br/ccivil_03/leis//8078.htm. Acesso em: 20 fev. 2020.

${ }^{6}$ MIRAGEM, Bruno. O direito do consumidor como direito fundamental. In: MARQUES, Cláudia Lima; MIRAGEM, Bruno (Orgs.). Doutrinas Essenciais de Direito do Consumidor. São Paulo: Editora Revista dos Tribunais, 2010. v. 2.

${ }^{7}$ TRETTEL, Daniela Batalha. Planos de saúde na visão do STJ e do STF. São Paulo: Verbatim, 2010.
} 
A complexidade do assunto não para por aí: enquanto determinadas situações fáticas - tais como efetivas internações domiciliares -, não obstante exclusões contratuais, eventualmente admitam a concessão de cobertura extraordinária em favor deste ou daquele serviço domiciliar, outras causam especial aversão aos mutualismos securitários. É o caso, por exemplo, de pacientes com doença de Alzheimer ou Parkinson, patologias que, embora exijam assistência de familiares e/ou cuidadores, definitivamente não implicam cuidados médicos-técnicos ininterruptos, muito menos hospitalização.

Em outras palavras, enquanto determinados quadros efetivamente necessitam, em domicílio, dos mesmos cuidados fornecidos em ambiente hospitalar, outros não passam de um conforto almejado pelos familiares, que buscam - de maneira censurável e até mesmo inconstitucional - transferir a terceiros (plano de saúde) não só os custos e a responsabilidade, como também o desgaste decorrente da atenção e dos cuidados de que os enfermos necessitam, seja pela velhice, seja por doenças crônicas, por exemplo. Daí porque examinar as nuances que envolvem o fornecimento de serviços de saúde em domicílio (home care) no âmbito dos contratos de planos de saúde é, insiste-se, missão extremamente complexa.

\section{Os planos de saúde e as coberturas obrigatórias}

Delimitar quais serviços devem ser obrigatoriamente cobertos pelos planos de saúde não é tarefa simples. Há, antes de tudo, a variável temporal, referente aos planos antigos, que são os contratados anteriormente à Lei Federal n. 9.656/1998, a denominada Lei dos Planos de Saúde (LPS), e também chamados de planos não regulamentados. Há décadas se discute se os referidos planos estariam ou não atingidos pela LPS, sobretudo porque continham (e contêm), em seus clausulados, limitações visivelmente incompatíveis com as novidades introduzidas pela referida lei. Verdade seja dita, com o julgamento da Ação Direta de Inconstitucionalidade n. 1.931, em fevereiro de $2018^{9}$, pelo Supremo Tribunal Federal (STF), o assunto ganhou um novo e importante capítulo. O STF, em síntese, sacramentou ser inaplicável a Lei Federal n. 9.656/1998 aos planos contratados anteriormente a ela. Com isso, pode-se afirmar, com segurança, que as coberturas assistenciais contempladas pelos planos antigos se pautam pelo conteúdo de seus clausulados, sendo admitidos, no máximo, temperos do CDC.

Superada a variável temporal, as coberturas assistenciais obrigatoriamente asseguradas pelos planos privados regulamentados decorrem, hierarquicamente, da referida Lei dos Planos de Saúde, das normas da Agência Nacional de Saúde

\footnotetext{
${ }^{8}$ BRASIL. Lei n. 9.656, de 3 de junho de 1998. Dispõe sobre os planos e seguros privados de assistência à saúde. Disponível em: http://www.planalto.gov.br/ccivil_03/leis/L9656compilado.htm. Acesso em: 20 fev. 2020.

${ }^{9}$ BRASIL. Ação Direta de Inconstitucionalidade n. 1.931. Disponível em: http://redir.stf.jus.br/paginadorpub/ paginador.jsp?docTP=TP\&docID=14968742. Acesso em: 20 fev. 2020.
} 
Suplementar (ANS) e, é claro, das cláusulas contratuais. Digno de nota que, ao contrário do que se pode imaginar, a liberdade contratual das operadoras, especialmente no que concerne às coberturas assistenciais, é mínima.

No sistema atual, os clausulados contratuais dos planos de saúde regulamentados devem estar necessariamente harmônicos com a LPS e com as normas regulamentadoras específicas do setor. Embora possam acrescer novas coberturas, as cláusulas jamais podem contrariar ou suprimir aquilo que a lei e/ou a agência reguladora já rotularam como sendo de natureza obrigatória. Daí o plano de saúde ser, nos termos do artigo 54 do CDC, um contrato de adesão por excelência.

$\mathrm{Na}$ prática, as coberturas assistenciais obrigatórias decorrem, em primeiro lugar, do artigo 10, caput, da LPS, cuja redação determina que serão obrigatoriamente cobertas todas as doenças e enfermidades listadas na Classificação Estatística Internacional de Doenças e Problemas Relacionados com a Saúde (CID), editada e publicada pela Organização Mundial da Saúde (OMS). O segundo dispositivo mais importante, em matéria de cobertura assistencial, é o artigo 12, também da LPS, cujos incisos arrolam, ainda que superficialmente, os tipos de serviços que são de cobertura obrigatória conforme as diferentes segmentações (ambulatorial, hospitalar com ou sem obstetrícia e odontológica). O inciso I estabelece, por exemplo, que o plano ambulatorial deve obrigatoriamente cobrir consultas médicas em todas as especialidades médicas reconhecidas pela Conselho Federal de Medicina (CFM), ao passo que o inciso II indica que a segmentação hospitalar deve contemplar, por exemplo, internações hospitalares, inclusive em centro de terapia intensiva, sem limitação de dias.

Os referidos incisos do artigo 12 da LPS, entretanto, definitivamente não esgotam o assunto, devendo ser necessariamente lidos em conjunto com as normas da ANS, em especial a Resolução Normativa (RN) n. 428/2017 ${ }^{10}$, conhecida por veicular o Rol de Procedimentos e Eventos em Saúde (RPES) hoje vigente. Esta norma, além de ratificar as disposições dos artigos 10 e 12 da LPS, as complementa e pormenoriza. A título de ilustração, veja-se que, no âmbito da segmentação ambulatorial, a dita resolução acresce, por exemplo, a obrigatoriedade de cobertura para consultas com nutricionista, fonoaudiólogo, terapeuta ocupacional e psicólogo.

Dito isto, cabe observar que, da leitura dos referidos dispositivos, não se localiza na LPS nem no corpo da RN n. 428/2017 uma lista de quais procedimentos/ exames/tratamentos têm de fato cobertura obrigatória. Os poucos procedimentos

\footnotetext{
${ }^{10}$ AGÊNCIA NACIONAL DE SAÚDE SUPLEMENTAR - ANS. Resolução n. 428, de 7 de novembro de 2017. Atualiza o Rol de Procedimentos e Eventos em Saúde, que constitui a referência básica para cobertura assistencial mínima nos planos privados de assistência à saúde, contratados a partir de $1^{\circ}$ de janeiro de 1999; fixa as diretrizes de atenção à saúde; e revoga as Resoluções Normativas - RN n 387 , de 28 de outubro de 2015, e RN n 407, de 3 de junho de 2016. Disponível em: https://www.ans.gov.br/component/ legislacao/?view=legislacao\&task=TextoLei\&format=raw\&id=MzUwMg==. Acesso em: 20 fev. 2020.
} 
nominalmente indicados pela LPS limitam-se à cirurgia plástica reconstrutora de mama decorrente de mutilação de tratamento de câncer (art. 10-A) e ao fornecimento de bolsas de colostomia, ileostomia e urostomia, sonda vesical de demora e coletor de urina (art. 10-B). Com exceção destes, a LPS não menciona individualmente outros procedimentos e/ou tratamentos. Então, como saber, por exemplo, se um exame de tomografia ou de ressonância magnética está ou não coberto?

A resposta está no rol de procedimentos obrigatórios. De acordo com o artigo 10, parágrafo $4^{\circ}$, da LPS, a amplitude das coberturas define-se pelas normas editadas pela ANS. Desde sua criação, cabe à agência reguladora, nos termos do artigo 4, inciso III, da Lei Federal n. 9.961/2000 ${ }^{11}$, editar periodicamente o Rol de Procedimentos e Eventos em Saúde, popularmente conhecido como o rol de procedimentos obrigatórios. Trata-se de uma lista extensa, atualizada a cada dois anos, que arrola todos os procedimentos de cobertura obrigatória.

Em resumo, portanto, a identificação quanto à obrigatoriedade de cobertura para este ou aquele serviço médico, no âmbito dos contratos de plano de saúde, pressupõe, além da consulta à LPS, ao corpo da RN n. 428/2017 (ou à norma que a suceder) e às cláusulas contratuais, o manuseio do mencionado rol de procedimentos obrigatórios.

\section{Os serviços domiciliares e os planos de saúde}

A LPS classifica os contratos privados de assistência à saúde em quatro segmentações: ambulatorial, hospitalar, obstetrícia e odontológica. Incorporando essa classificação, a $\mathrm{RN} \mathrm{n.} 85 / 2004^{12}$ da ANS, ao tratar das regras para registro dos planos de saúde, elenca as 12 possíveis combinações de produtos passíveis de comercialização pelas operadoras (item 2 do Anexo II).

De maneira grosseira, mas suficientemente assertiva, pode-se concluir que o plano ambulatorial visa a cobrir consultas e exames simples; o plano hospitalar confere cobertura para internação hospitalar; a obstetrícia, sempre acompanhada da segmentação hospitalar, cobre eventos relacionados ao parto e ao recém-nascido; e o plano odontológico compreende consultas, exames e procedimentos inerentes à odontologia. Observe-se que não existe a segmentação domiciliar. Logo, revela-se natural questionar se há, no âmbito dos planos de saúde, cobertura para serviços de saúde a serem prestados em domicilio. A resposta para esta pergunta exige consulta à legislação.

\footnotetext{
${ }^{11}$ BRASIL. Lei n. 9.961, de 28 de janeiro de 2000. Cria a Agência Nacional de Saúde Suplementar - ANS e dá outras providências. Disponível em: http://www.planalto.gov.br/ccivil_03/leis/I9961.htm. Acesso em: 20 fev. 2020.

${ }^{12}$ AGÊNCIA NACIONAL DE SAÚDE SUPLEMENTAR - ANS. Resolução n. 85, de 7 de dezembro de 2004. Dispõe sobre a concessão de Autorização de Funcionamento das operadoras de Planos de Assistência à Saúde, e dá outras providências. Disponível em: http://www.ans.gov.br/component/legislacao/?view=legi slacao\&task=TextoLei\&format=raw\&id=ODgx. Acesso em: 20 fev. 2020.
} 
Da leitura do artigo 12 da LPS, extrai-se que os únicos serviços de saúde domiciliares cujo fornecimento é de cobertura obrigatória são os tratamentos antineoplásicos de uso oral. Os tratamentos antineoplásicos consistem, na prática, de medicamentos utilizados nos tratamentos de câncer, voltados a destruir neoplasmas e a inibir o crescimento e a disseminação de tumores. Ainda que limitados àqueles medicamentos arrolados pela ANS, sua cobertura é sempre obrigatória, seja em planos hospitalares, seja em planos exclusivamente ambulatoriais.

Fora essa referência, a LPS faz mais uma única menção a serviços domiciliares: ao tratar das bolsas de colostomia, ileostomia e urostomia, sonda vesical de demora e coletor de urina com conector, a lei preconiza, expressamente, ser obrigatório fornecimento destas para uso hospitalar, ambulatorial ou domiciliar (art. 10-B). Portanto, ao se falar em serviços de saúde domiciliares de cobertura obrigatória, deve-se acrescer, aos medicamentos antineoplásicos de uso oral, os referidos itens.

Ressalvadas essas referências, a Lei n. 9.656/1998 não traz qualquer outra previsão relativa a serviços domiciliares que devam ser eventualmente cobertos pelos planos de saúde. A exploração deste tema, assim, exige adentrar as normas regulamentadoras. Destas, destaca-se a já referida RN n. 428/2017, que, além de repetir as disposições da LPS, contempla dois comandos: o primeiro, no sentido de que, caso ofereça cobertura para internação domiciliar em substituição à internação hospitalar, a operadora deve seguir as exigências das normas sanitárias (art. 14, caput); e o segundo, no sentido de que, caso ofereça assistência domiciliar que não se dê em substituição à internação hospitalar, esta deve obedecer à previsão contratual ou à negociação entre as partes (art. 14, parágrafo único).

Contendo comandos na mesma direção, é citável a também já mencionada RN n. 85/2004, cujo Anexo II, ao elencar exemplos de serviços e coberturas adicionais - de caráter facultativo, portanto -, inclui os serviços de assistência/ internação domiciliar (item 13.1.1). Trata-se, destarte, de serviços que, para serem exigíveis pelos beneficiários, devem estar expressamente inseridos no clausulado do contrato. Corroborando esta conclusão, citável o seguinte trecho plasmado pelo Superior Tribunal de Justiça (STJ):

[...] Na Saúde Suplementar, o tratamento médico em domicílio não foi incluído no rol de procedimentos mínimos ou obrigatórios que devem ser oferecidos pelos planos de saúde. [...] o home care não consta das exigências mínimas para as coberturas [...] (Recurso Especial n. 1.378.707/RJ) ${ }^{13}$.

\footnotetext{
${ }^{13}$ SUPERIOR TRIBUNAL DE JUSTIÇA - STJ. Recurso Especial n. 1.378.707/RJ. Disponível em: https://ww2. stj.jus.br/processo/revista/inteiroteor/?num_registro=201300995112\&dt_publicacao=15/06/2015. Acesso em: 20 fev. 2020.
} 
Em outras palavras, no que tange aos contratos de planos de saúde e aos serviços prestados em domicílio, considerando o que dispõem as normas regulamentadoras aplicáveis, é possível alcançar as seguintes conclusões: (i) os únicos serviços domiciliares de cobertura obrigatória por todo e qualquer plano de saúde são os medicamentos antineoplásicos de uso oral e as referidas bolsas/itens coletores; (ii) as operadoras têm a faculdade, não a obrigação, de oferecer cobertura para internação domiciliar em substituição à internação hospitalar; assim como (iii) as operadoras têm a faculdade, não a obrigação, de oferecer cobertura para os demais serviços domiciliares que não caracterizem substituição à internação hospitalar.

\section{O home care e a confusão terminológica}

Apresentado, ainda que de maneira sintética, o regime jurídico dos serviços domiciliares no âmbito dos contratos de planos de saúde, mostra-se necessário registrar que a complexidade do assunto conta com outra particularidade: a confusão terminológica que envolve a matéria. Primeiro porque a própria expressão home care é, por si só, carregada de notória vagueza semântica. Veja-se que a palavra home remete a domicílio, ao passo que o termo care significa cuidado. Combinadas, podem traduzir qualquer serviço que implique cuidados/tratamentos de saúde em domicílio e descrever, portanto, desde uma complexa internação domiciliar até uma simples sessão de fisioterapia em domicílio.

Além da expressão home care, outras variações terminológicas - tais como atendimento domiciliar, assistência domiciliar, tratamento domiciliar, internação domiciliar, enfermagem $24 \mathrm{~h}$ e atenção domiciliar - são igualmente utilizadas na área de saúde para referir serviços prestados em ambiente domiciliar, sejam eles quais forem. Ocorre que a utilização dessas expressões se dá de maneira confusa e sem maior rigor semântico ou técnico, constatação que se aplica não só a prestadores de serviços de saúde, como também a médicos, advogados e magistrados.

Esse contexto é, sem qualquer dúvida, decorrente também dos textos normativos que tratam de serviços domiciliares no âmbito dos serviços públicos. É possível observar que, enquanto algumas normas (e órgãos) utilizam determinadas variações terminológicas, outras utilizam expressões diversas. E mesmo quando empregadas expressões idênticas, não se pode afirmar que seus significados sejam equivalentes, tampouco que contemplem situações semelhantes.

Veja-se, por exemplo, que a Lei Federal n. 8.080/1990 ${ }^{14}$ - conhecida como Lei Orgânica do Sistema Único de Saúde (SUS) - fala unicamente em atendimento domiciliar e em internação domiciliar. A Portaria do Ministério da Saúde (MS) n.

\footnotetext{
${ }^{14}$ BRASIL. Lei n. 8.080, de 19 de setembro de 1990. Dispõe sobre as condições para a promoção, proteção e recuperação da saúde, a organização e o funcionamento dos serviços correspondentes e dá outras providências. Disponível em: http://www.planalto.gov.br/ccivil_03/leis/L8080.htm. Acesso em: 20 fev. 2020.
} 
$2.416 / 1998^{15}$, que estabelece os requisitos para credenciamento de hospitais e critérios para realização de internação domiciliar no SUS, fala, por sua vez, apenas em internação domiciliar. Já a Resolução da Diretoria Colegiada (RDC) n. 11/2006 da Agência Nacional de Vigilância Sanitária (Anvisa), norma que dispõe sobre o regulamento técnico de funcionamento de serviços que prestam atenção domiciliar, fala tanto em assistência domiciliar quanto em internação domiciliar, sendo ambas espécies do gênero atenção domiciliar.

No que tange especificamente à saúde suplementar, a ANS, que é a agência reguladora especificamente criada para fiscalizar e normatizar esse setor, utiliza a seguinte classificação: internações domiciliares, compreendidas como substitutas de internação hospitalar; e assistências domiciliares, expressão genérica que contemplaria todos os demais atendimentos domiciliares que não se confundem com a primeira.

A impressão que se tem é de que cada órgão instituiu seu próprio microssistema, estabelecendo conceitos que focam unicamente em suas próprias atividades e organização interna, sem se preocupar com os demais atores e sistemas que igualmente participam e se envolvem, de uma forma ou de outra, no fornecimento dos serviços de saúde. Daí a confusão terminológica apontada no título deste capítulo.

Feito esse registro - que será fundamental para a compreensão da jurisprudência a ser a seguir apresentada e avaliada - e considerando que este trabalho dedica-se a examinar, especificamente, os serviços domiciliares no âmbito dos planos de saúde, parece-nos lógico reconhecer que a terminologia a ser privilegiada (inclusive quanto aos respectivos significados), sobretudo para fins de análise da existência ou não de cobertura contratual, é aquela aplicada pela ANS e por seus textos normativos.

\section{Panorama jurisprudencial}

Conforme explicitado, do ponto de vista legal e normativo, as operadoras estão obrigadas a cobrir, em ambiente domiciliar, apenas e tão somente os medicamentos antineoplásicos e as bolsas coletoras. Fora esses específicos serviços, o fornecimento de todas as demais espécies de atendimento domiciliar - seja uma mera consulta médica, seja uma completa instalação de internação domiciliar em substituição à hospitalização - está, em tese, sujeito às disposições contratuais do caso concreto.

\footnotetext{
${ }^{15}$ MINISTÉRIO DA SAÚDE - MS. Portaria n. 2.416, de 23 de março de 1998. Estabelece requisitos para credenciamento de Unidades Hospitalares e critérios para realização de internação em regime de hospital-dia geriátrico. Disponível em: http://bvsms.saude.gov.br/bvs/saudelegis/gm/1998/ prt2414_23_03_1998.html. Acesso em: 20 fev. 2020.

${ }^{16}$ AGÊNCIA NACIONAL DE VIGILÂNCIA SANITÁRIA - ANVISA. Resolução da Diretoria Colegiada $n$. 11, de janeiro de 2006. Dispõe sobre o Regulamento Técnico de Funcionamento de Serviços que prestam Atenção Domiciliar. Disponível em: http://bvsms.saude.gov.br/bvs/saudelegis/anvisa/2006/ res0011_26_01_2006.html. Acesso em: 20 fev. 2020.
} 
Como regra, os planos de saúde no Brasil não cobrem serviços de saúde prestados em ambiente domiciliar, sejam eles quais forem; os produtos padrões hoje disponibilizados no mercado brasileiro tendem a expressamente enquadrá-los como excluídos de cobertura. Logo, caso haja interesse em contar com essa cobertura, cabe ao contratante consultar sua operadora sobre a possibilidade de contratação. Como tais serviços são considerados adicionais (opcionais), além de sua precificação ser realizada à parte, a operadora pode ou não disponibilizar sua contratação. Não há, entretanto, qualquer obrigatoriedade nesse sentido.

Não é incomum, no entanto, operadoras que, por liberalidade, disponibilizam serviços domiciliares aos clientes. Quando isso ocorre, os serviços fornecidos, logicamente, limitam-se às regras, condições e situações pré-determinadas por cada operadora. Ressalvadas essas situações excepcionais - em que as operadoras admitem a contratação adicional de cobertura de serviços domiciliares e/ou os disponibilizam por liberalidade -, a regra geral é a de que os planos de saúde, insiste-se, não cobrem serviços de saúde em ambiente domiciliar.

Em virtude dessa realidade, as solicitações de autorização para cobertura de serviços e tratamentos domiciliares, cada vez mais comuns, como regra, são negadas. Como consequência, face aos fenômenos jurídicos e sociais acima comentados - em especial a incidência das normas de proteção dos consumidores e a tendência de judicialização dos conflitos envolvendo serviços de saúde -, tais situações tendem a ser levadas ao Poder Judiciário.

Uma primeira avaliação do panorama jurisprudencial envolvendo cobertura contratual para home care permite constatar, antes de tudo, que tais processos, em grande parte, compartilham da realidade que é comum aos litígios que discorrem sobre limitações de cobertura assistencial dos planos de saúde: seja pela incidência das normas do CDC, seja pela invocação do direito à saúde e/ou de princípios constitucionais, seja pela máxima segundo a qual a operadora não poderia recusar um tratamento prescrito pelo médico assistente, as demandas vinham sendo (e em boa parte ainda o são) preponderantemente resolvidas de maneira favorável aos beneficiários.

O refúgio das operadoras limitava-se quase que exclusivamente à tentativa de demonstrar, em juízo e no mais das vezes pericialmente, que os serviços domiciliares pretendidos pelo beneficiário não eram, de fato, necessários. Alternativamente, procurava-se demonstrar que o beneficiário necessitaria apenas de cuidados básicos - vinculados, por exemplo, à alimentação, à higiene, ao vestuário ou à ministração de medicamentos - cuja responsabilidade haveria de recair sobre os familiares (ou sobre um cuidador contratado), não à operadora, visto estar ausente a necessidade de cuidados médicos técnicos ininterruptos. Argumentos jurídicos, atrelados a exclusões puramente contratuais, raramente vingaram judicialmente. 
Esse panorama historicamente gerou revolta das operadoras. Ainda que determinadas situações pudessem de fato justificar, por exemplo, internações domiciliares, inúmeras outras não passavam (e não passam) de tentativas censuráveis de transferir ao plano de saúde o desgaste e os custos dos cuidados exigidos por entes acamados e/ou debilitados pela idade e por doenças incapacitantes - cuidados estes que, constitucionalmente, competiriam aos familiares e/ou que poderiam ser terceirizados a cuidadores ou a casas geriátricas, por exemplo. Ao se proliferarem, decisões judiciais acolhendo tais pretensões em desfavor dos planos de saúde impulsionaram uma indústria sombria de interesses nefastos, cujos maiores beneficiados são médicos, advogados e prestadores de home care.

Felizmente, graças a recentes precedentes judiciais prolatados pelo STJ, tal cenário vem se relativizando e ganhando um equilíbrio que, embora permaneça extrapolando as disposições normativas e contratuais, mostra-se mais sustentável, razoável e tolerável. Refere-se, especialmente, à decisão decorrente do julgamento do Recurso Especial n. 1.537.301/RJ, de relatoria do ministro Ricardo Villas Boas Cueva, julgado em 18 de agosto de $2015^{17}$.

No referido precedente, a autora, beneficiária de plano de saúde, relatou ser portadora de doenças e complicações que a tornavam incapaz e limitada ao leito. Destacou que se encontrava hospitalizada, tendo recebido alta médica para que passasse a receber, em domicílio, "acompanhamento home care 24 horas", com toda a estrutura hospitalar necessária. Segundo se extrai da decisão, o plano de saúde forneceu tais serviços apenas por um mês, interrompendo-o na sequência, o que originou a demanda judicial. A operadora defendeu sua conduta explicando que ocorrera apenas a aprovação temporária do serviço domiciliar e, mesmo assim, por liberalidade, na medida em que se tratava de um serviço sem previsão contratual. Interposto recurso especial por parte da operadora do plano de saúde, o STJ manteve a decisão do Tribunal de Justiça do Rio de Janeiro, que decidira favoravelmente à pretensão da consumidora. Ocorre que, em sua decisão, o STJ empregou premissas e conclusões cuja importância extrapola, e muito, os limites do caso concreto. Em sua fundamentação, inicialmente, a decisão lembrou a incidência das normas do CDC na relação jurídica lá examinada. No mérito, embora reconhecendo as limitações do rol de procedimentos obrigatórios da ANS, concluiu ser abusiva a cláusula contratual que exclui a cobertura da internação domiciliar em substituição à internação hospitalar. Em que pese ter considerado a referida cláusula excludente como sendo abusiva, a decisão é suficientemente clara no sentido de que esse entendimento se restringe apenas à internação domiciliar como substituição à internação hospitalar, o que por si só autoriza concluir

\footnotetext{
${ }^{17}$ SUPERIOR TRIBUNAL DE JUSTIÇA - STJ. Recurso Especial n. 1.537.301/RJ. Disponível em: https://ww2. stj.jus.br/processo/revista/inteiroteor/?num_registro=201500489012\&dt_publicacao=23/10/2015. Acesso em: 20 fev. 2020.
} 
e defender que as exclusões para os demais serviços de saúde domiciliares que não se enquadrem nesta categoria (tais como exames, consultas e curativos, todos tipicamente realizados em caráter ambulatorial) são lícitas.

O precedente parte da premissa de que a conversão da internação hospitalar em internação domiciliar seria, ao mesmo tempo, benéfica ao paciente e vantajosa à operadora: ao paciente porque lhe permitiria deixar o ambiente hospitalar (diminuindo riscos de infecções e demais doenças) e ficar próximo de sua família, em seu lar, inclusive aumentando as chances de recuperação; e seria vantajosa à operadora na medida em que, em muitos casos, a desospitalização de um paciente viabilizaria a otimização de leitos hospitalares e a redução de custos.

O precedente elenca, ainda, as condições que devem necessariamente se fazer presentes no caso concreto para que a cobertura do tratamento domiciliar em substituição à internação hospitalar seja de fato exigível do plano de saúde, a saber: a residência deve ter condições estruturais para suportar o serviço; o quadro clínico do paciente deve efetivamente exigir atendimento domiciliar; o serviço domiciliar deve estar prescrito pelo médico assistente; deve haver solicitação (e apoio) da família nesse sentido; o paciente deve estar de acordo com sua transferência para o domicílio; e a conversão da internação hospitalar em internação domiciliar não pode afetar o equilíbrio contratual, isto é, os custos do atendimento domiciliar não podem superar os custos da hospitalização.

De acordo com a referida decisão, portanto, os requisitos acima citados, consagrados pelo STJ, devem ser sempre observados, ressalvadas as situações em que houver regras próprias já previstas em contrato. Havendo previsão contratual em favor de serviço equivalente, com estabelecimento de regras próprias, conclui-se, logicamente, que estas devem prevalecer. Na ausência de regras contratuais, por outro lado, os requisitos descritos pelo precedente acima mencionado devem guiar a solução a ser adotada no caso concreto. Sem dúvida, trata-se de uma decisão mais equilibrada, razoável e ponderada.

\section{Ponto de equilíbrio}

A partir do mencionado leading case, conclui-se o seguinte: (i) a exclusão de cobertura de serviços de saúde domiciliares que não se enquadrem como internação domiciliar em substituição à hospitalização é, como regra, lícita; (ii) a eventual abusividade limita-se unicamente à exclusão de cobertura para internação domiciliar que age como substituta de internação hospitalar; (iii) caso o serviço domiciliar esteja previsto no contrato, as regras contratuais devem prevalecer; (iv) na ausência de regras contratuais, o fornecimento da internação domiciliar deve estar condicionado ao preenchimento dos requisitos veiculados na mencionada decisão judicial; e (v) a internação domiciliar não pode ser mais dispendiosa do que a hospitalização. 
Digno de nota que o precedente acima comentado não é único. Trilhando caminho muito parecido, cita-se também o Recurso Especial n. 1.378.707/RJ, de relatoria do ministro Paulo de Tarso Sanseverino, julgado em 26 de maio de 2015, que considerou obrigatória a cobertura do serviço de home care pleiteado por beneficiário de plano de saúde. A decisão deixou claro, contudo, que o serviço domiciliar lá tratado estava sendo considerado de cobertura obrigatória por constituir "desdobramento do tratamento hospitalar contratualmente previsto". O precedente igualmente consignou que, na ausência de contratação específica, "o serviço de internação domiciliar (home care) pode ser utilizado em substituição à internação hospitalar". O decisum grifou, outrossim, que tal entendimento vale conquanto observados determinados requisitos, incluindo a indicação do médico assistente, a concordância do paciente e, novamente, a não afetação do equilíbrio contratual.

Mais recentemente, esse panorama jurisprudencial foi enriquecido com o julgamento do Recurso Especial n. 1.599.436/RJ, também de relatoria do ministro Paulo de Tarso Sanseverino, julgado em 23 de outubro de $2018^{18}$. A referida decisão, além de confirmar o entendimento acima comentado referente às internações domiciliares ${ }^{19}$, acrescentou que, em determinadas situações, tampouco poderia ser excluído, de antemão, o fornecimento dos demais serviços de saúde em domicílio, da cobertura do plano de saúde.

O precedente parte da premissa de que, em determinados casos, à semelhança do que acontece com as internações domiciliares, o fornecimento dos demais serviços de saúde em domicílio, além de ser benéfico ao paciente, também pode ser, na visão de médio prazo, vantajoso à operadora do plano de saúde, na medida em que evitaria o risco de agravamento do quadro clínico do paciente e, principalmente, o risco de hospitalização, da qual decorreriam custos muito maiores.

A decisão é clara, no entanto, no sentido de que deve sempre haver um exame das peculiaridades e da complexidade do tratamento pretendido, de modo a se averiguar se, no caso concreto, o fornecimento dos serviços em ambiente domiciliar de fato permite essa compensação, garantindo o necessário equilíbrio contratual. Em caso negativo, a exclusão de cobertura pode e deve prevalecer. Disso se conclui que, embora os demais serviços de saúde domiciliares sejam passíveis de exclusão contratual, em determinados casos seu fornecimento pode ser efetivamente mais

\footnotetext{
${ }^{18}$ SUPERIOR TRIBUNAL DE JUSTIÇA - STJ. Recurso Especial n. 1.599.436/RJ. Disponível em: https://ww2.stj. jus.br/processo/monocraticas/decisoes/?num_registro=201903038834\&dt_publicacao=06/02/2020. Acesso em: 20 fev. 2020.

${ }^{19}$ Segue importante trecho da decisão: “No que tange à cobertura do serviço de 'home care', a jurisprudência desta Corte Superior é pacífica no sentido de que o 'home care', na modalidade 'internação domiciliar' (substituto de uma internação hospitalar), deve ser oferecido pelas operadoras de plano de saúde, independentemente de previsão contratual, tendo em vista as vantagens do ambiente domiciliar, em comparação com o hospitalar, do ponto de vista do bem-estar e da recuperação do paciente, bem como as vantagens financeiras para operadora, em termo de redução de custos".
} 
vantajoso à operadora, pois evitará (ou pelo menos reduzirá) o risco de uma provável hospitalização. Nessas hipóteses, segundo a mencionada decisão, eventual negativa de cobertura, ainda que não se trate de internação domiciliar em substituição à internação hospitalar, pode vir a ser considerada abusiva.

Da leitura conjunta dos mencionados precedentes, fica evidente que, ao se tratar de serviços de saúde domiciliares no universo da saúde suplementar, é de máxima importância que se esclareçam sempre quais são as condições clínicas do paciente e os serviços que se pretende que sejam efetivamente fornecidos em cada caso. Não basta a mera indicação de home care (ou de atendimento domiciliar ou de assistência domiciliar), visto que tal expressão carrega pluralidade de possíveis significados.

Ao recepcionarem solicitações de autorização de serviços domiciliares, intitulados ou não como home care, passa a ser recomendável que as operadoras não se limitem à análise fria do clausulado e atentem às particularidades fáticas do caso concreto. Na hipótese de o beneficiário pretender internação domiciliar em substituição à internação hospitalar, e estando a solicitação acompanhada dos demais requisitos acima tratados, incluindo a manutenção do equilíbrio contratual, tudo indica que a autorização deva ser considerada, visto que, do contrário, bastará o manejo de medida judicial para que o serviço seja compulsoriamente implementado, acrescido dos demais custos das despesas judiciais. A mesma consideração vale para hipóteses em que o serviço pretendido - ainda que não se caracterizando como substituição de internação hospitalar - comprovadamente servir para fulminar (ou pelo menos reduzir) o risco de uma provável hospitalização. Nesses casos, se houver efetivo risco de hospitalização, a implementação do atendimento domiciliar igualmente merece ser considerada pela operadora. Há de se ressalvar, logicamente, que essa compensação só poderá ser cogitada nos casos em que o beneficiário estiver vinculado a plano de saúde que contemple a segmentação hospitalar.

De outro lado, caso a solicitação não se revele como substituição de internação hospitalar - o que compete à operadora apurar, preferencialmente através de perícia in loco -, o indeferimento da autorização, por ausência de cobertura contratual, é, como regra, perfeitamente lícito, sustentável e defensável (excetuadas, repete-se, situações diferenciadas, de caráter extraordinário, em que o atendimento domiciliar pretendido comprovadamente servir para evitar, ou pelo menos reduzir, o risco de uma provável hospitalização).

Da mesma forma, a negativa de cobertura poderá ser legitimamente realizada naqueles casos em que, mesmo tratando-se de efetiva substituição de internação hospitalar, restar comprovado que a implementação de internação domiciliar implicará desequilíbrio contratual (do ponto de vista econômico), comparando os custos das diárias, por exemplo. 
Tais premissas, embora não reflitam exatamente aquilo que se extrai das normas específicas dos planos de saúde, revelam-se, sem qualquer dúvida, como mais razoáveis e toleráveis, sobretudo quando comparadas ao atual cenário jurisprudencial. Parecem identificar um meio-termo equilibrado - sempre condicionado e atento às peculiaridades fáticas, médicas e econômicas do caso concreto -, que não desprotege os consumidores nem desprestigia os contratos de planos de saúde e suas disposições. Esse ponto de equilíbrio mostra-se mais ajustado e compatibilizado com os valores e princípios constitucionais que guiam o ordenamento jurídico hoje em vigor.

Resta aguardar que esta orientação se consolide, se propague e passe a representar, definitivamente, o entendimento jurisprudencial brasileiro. Não mais se sustentam decisões judiciais que se limitam a julgar esses litígios com base em ditames pré-estabelecidos, sem nenhuma relação ou identidade com o caso concreto, em benefício cego aos consumidores e à revelia das particularidades fáticas, das normas regulamentadoras e dos clausulados contratuais.

\section{Considerações finais}

Examinar os serviços de saúde prestados em ambiente domiciliar e os contratos de assistência privada à saúde é definitivamente uma tarefa complexa, que engloba diversas variáveis jurídicas, sociais e econômicas. Conforme explicitado, a constatação quanto à existência ou não de cobertura contratual pelo plano de saúde está condicionada às peculiaridades fáticas do caso concreto, especialmente no que tange ao clausulado ao qual o beneficiário está vinculado e ao tipo de serviço domiciliar efetivamente pretendido, intitulado ou não como home care.

Do ponto de vista legal, considerando a LPS e as normas regulamentadoras decorrentes da ANS, os únicos serviços de saúde domiciliares considerados como de cobertura obrigatória são os tratamentos antineoplásicos de uso oral e o fornecimento de itens/bolsas coletoras (colostomia, ileostomia e urostomia, sonda vesical de demora e coletor de urina). Todos os demais serviços de saúde fornecidos em ambiente domiciliar são passíveis de exclusão contratual; em outras palavras, do ponto de vista legal e normativo, não são de cobertura obrigatória.

Judicialmente, no entanto, o panorama que se observa é mais delicado. Historicamente, as demandas judiciais versando sobre essa matéria sempre foram (e em grande parte ainda são) resolvidas com os mesmos fundamentos utilizados na maioria dos litígios que discutem limitações de coberturas assistenciais. $\mathrm{Na}$ prática, predominantemente com base nas normas de proteção do consumidor, tais litígios costumam ser resolvidos favoravelmente aos beneficiários, independentemente da existência de disposições contratuais excludentes. 
Nos últimos anos, contudo, esse cenário começou a se modificar e, graças a recentes e emblemáticos precedentes do STJ, parece ser possível projetar uma realidade mais justa e equilibrada, a qual, ao mesmo tempo em que resguarda os beneficiários/consumidores à luz de sua real situação fática, não desconsidera as operadoras, os contratos de planos de saúde e suas limitações.

Em resumo, incorporando as premissas decorrentes dos referidos precedentes - e considerando o atual cenário judicial, em que demandas envolvendo coberturas assistenciais, inclusive de home care, são na esmagadora maioria das vezes julgadas indiscriminadamente em favor dos beneficiários/pacientes -, podem-se defender, como pilares fundamentais ao estabelecimento de um verdadeiro ponto de equilíbrio para esta matéria, as seguintes máximas: (i) a exclusão de cobertura para serviços de saúde domiciliares que não se caracterizem como substitutos de internação hospitalar é, como regra, lícita, ressalvados casos extraordinários cujo fornecimento comprovadamente servir para evitar provável hospitalização; (ii) eventual abusividade prima facie limita-se, no máximo, à exclusão de cobertura de internação domiciliar que age como substitutivo de internação hospitalar; (iii) caso o serviço domiciliar esteja previsto como coberto no contrato, as regras contratuais devem prevalecer; (iv) na ausência de regras contratuais, o fornecimento da internação domiciliar deve estar condicionado ao preenchimento dos requisitos veiculados nas decisões judiciais citadas; e (v) a internação domiciliar não pode ser mais dispendiosa do que a hospitalização, assim como os custos de eventual assistência domiciliar não podem ser superiores aos custos de eventual hospitalização.

Passa a ser de suma importância, portanto, que as operadoras, ao recepcionarem solicitações de cobertura para serviços domiciliares, não se restrinjam àquilo que consta nos contratos e passem a privilegiar, acima de tudo, as condições clínicas do paciente e a cotejá-las ao serviço efetivamente pretendido. Na hipótese de se tratar de efetiva internação domiciliar em substituição à hospitalização, os requisitos acima veiculados devem ser analisados e, se preenchidos no caso concreto, a autorização do serviço desejado, ainda que ausente a previsão contratual, merece ser considerada, o mesmo valendo para os demais serviços, desde que o beneficiário demonstre que seu fornecimento evitará uma provável hospitalização.

Embora este entendimento não obedeça, inteiramente, àquilo que se extrai da legislação e das normas regulamentadoras específicas do sistema de saúde suplementar, ele representa um caminho mais razoável e aceitável, visto que privilegia, ao mesmo tempo, o sistema protetivo dos consumidores, os valores e princípios constitucionais, as condições clínicas específicas do paciente e as limitações contratuais do plano de saúde.

Verdade seja dita, os mencionados precedentes não geraram, até o momento, o efeito desejado nos tribunais estaduais, pelo menos não de maneira suficiente. Sua influência nas decisões locais ainda é tímida. Decisões individualistas, 
exageradamente centradas nas normas protetivas dos consumidores, ainda representam a posição majoritária. Resta desejar que a linha jurisprudencial acima comentada se propague e passe a nortear a solução dos litígios envolvendo serviços de saúde domiciliares e planos de saúde.

\section{Referências Bibliográficas}

CARLINI, Angélica. Judicialização da saúde pública e privada. Porto Alegre: Livraria do Advogado, 2014.

FACCHINI NETO, Eugênio. Reflexões históricos-evolutivas sobre a Constitucionalização do Direito Privado. In: SARLET, Ingo Wolfgang (Org.). Constituição, direitos fundamentais e direito privado. 3. ed. Porto Alegre: Livraria do Advogado, 2010.

MIRAGEM, Bruno. O direito do consumidor como direito fundamental. In: MARQUES, Cláudia Lima; MIRAGEM, Bruno (Orgs.). Doutrinas Essenciais de Direito do Consumidor. São Paulo: Editora Revista dos Tribunais, 2010. v. 2.

SCAFF, Fernando Campos. Direito à saúde no âmbito privado: contratos de adesão, planos de saúde e seguro-saúde. São Paulo: Saraiva, 2010.

SCHULZE, Clenio Jair; NETO, João Pedro Gebran. Direito à saúde: análise à luz da judicialização. Porto Alegre: Verbo Jurídico, 2015.

TRETTEL, Daniela Batalha. Planos de saúde na visão do STJ e do STF. São Paulo: Verbatim, 2010.

Augusto Franke Dahinten - Mestrado em Direito pela Pontifícia Universidade Católica do Rio Grande do Sul (PUC-RS); especialização em Direito Internacional Público e Privado pela Universidade Federal do Rio Grande do Sul (UFRGS); especialização em Direito Ambiental Nacional e Internacional pela UFRGS; MBA em Direito Empresarial com ênfase em Direito Tributário pelo Instituto de Desenvolvimento Cultural. Advogado. Porto Alegre/RS, Brasil. E-mail: gutodahinten@yahoo.com.br

Bernardo Franke Dahinten - Doutorando em Direito pela Pontifícia Universidade Católica do Rio Grande do Sul (PUC-RS); mestrado em Direito pela PUC-RS; especialização em Direito Médico pelo Verbo Jurídico; especialização em Direito Empresarial pela PUC-RS; especialização em Direito Imobiliário, Contratos e Responsabilidade Civil pelo Instituto de Desenvolvimento Cultural. Advogado. Porto Alegre/RS, Brasil. 